Mike Halling

$2 / 27 / 92$

PBAR NOTE 528

\title{
Measurement of $D->A$ momentum aperture and test of $D->A$ field qualities
}

The data presented here were taken during two shifts dedicated to D->A studies. The goal during both of these study periods was a test of the field quality of the D->A channel devices, but for the first study period on 10/21/91 the TBT system was not operational so we simply measured the transfer efficiency as a function of momentum. The conclusion from these measurements is as follows: 1 ) The momentum aperture of the D->A channel is smaller than expected. 2) The restriction is in physical space is somewhere near A:IKIK. 3) The field quality of the injection channel devices is adequate.

\section{MOMENTUM APERTURE LIMTTS}

Figure 1 shows the measured efficiency with both shutters open using the standard reverse proton magnet settings. The efficiency is about $100 \%$ from the very edge of the momentum aperture, 628700, to a point close to the first shutter. At this point the efficiency takes a sharp dive. The full range with good efficiency is about $0.3 \% \mathrm{dp} / \mathrm{p}$. The shutter location was derived from the energy spectrum of reverse protons injected with the injection shutter closed shown in Figure 2. The dispersion at A:IKIK is 9.8 meters, therefore the effective horizontal aperture near the injection kicker is about $27 \mathrm{~mm}$. Figure 3 shows a drawing of the the ferrite and beam gap in the kicker with the beam size derived from these measurements. The measured aperture is almost a factor of two smaller than the physical aperture. The gap between the shutter and the edge of the gap is $0.21 \%$ in $\mathrm{dp} / \mathrm{p}$, or $20 \mathrm{~mm}$; which was verified by an examination of the design drawings.

Local bumps at the A:IKIK will change the location of the injection kicker in revolution frequency. To identify the source of the losses we used a local bump that caused an orbit distortion shown in Figure 4. The bump we found on the parameter page was not 
local, but we only had a few minutes to complete the measurement and had to make do with what we had. With the bump in place we measured good transfer efficiency well past the endpoint of the earlier measurements, see Figure 1 . The high momentum aperture limit, however, moved in by the same amount.

\section{FIELD QUALITY MEASUREMENTS}

During the second study period on $1 / 12 / 92$ we tested the field quality of $A:$ IKIK by measuring injection oscillations in the debuncher as a function of momentum. About 10 bunches of reverse protons were captured at $628724 \mathrm{HZ}$ in a bucket to bucket transfer using ARF1. These were either accelerated or deacellerated to the desired energy and then transferred to the debuncher through the D->A line. These measurements were made more difficult by the fact that the some beam was lost as ARF1 changed it's energy, leaving too little beam to trigger the BPM system. We often transferred about $1 \times 10 * * 10$ protons, but waited for as many as 20 pulses for a TBT trigger.

The debuncher TBT system was used to detect injection oscillations that would arise if the off momentum beam encountered different fields than the central momentum beam. The dispersion through most of the $D->A$ line is about 1 meter, so this test was most sensitive to field variations in $A: I K I K$ where the dispersion is 9.8 meters.

Figures 5-8 show the sensitivity of the TBT measurements to changes in the strength of several D- $>$ A channel devices. A change of $10 \%$ in $A:$ IKIK or $D: E K T K$ gives about $6 \mathrm{~mm}$ injection oscillations. A change of about $1.5 \%$ in any of the septa gives about $10 \mathrm{~mm}$ injection oscillations. During stacking a change of about 4 volts on any one septa is visible in the $D->A$ efficiency, i.e. we start to be sensitive to oscillations of about $4 \mathrm{~mm}$. In the A->D direction $4 \mathrm{~mm}$ oscillations should be insignificant.

Figures 9-14 show the TBT measurements taken at different transfer momenta. The bulls eye plot has been blown up to show more detail. There is some evidence in Figures 9-14 of dispersive 
mismatching. At 628717 there is a clear $2 \mathrm{~mm}$ oscillation not present at 628724 . At 628740 there is an oscillation of about the same size in the opposite direction. Although visible, this small mismatch is most likely not the cause of the momentum restriction in the $D->A$ channel. In addition, if the mismatch is caused by field non-uniformity it must be a combination of one of the kickers and one of the septa since the observed oscillations are at an angle of 45 degrees to either device. Oscillations of a few millimeters are in fact expected due to the fact that the $D->A$ line is not dispersion matched.

\section{CONCLUSION}

The momentum aperture of the D->A channel is restricted by a physical limitation somewhere near the injection kicker. The effective beam size in the injection kicker is much smaller than the good field region of about $50 \mathrm{~mm}$. Some effects of dispersion mis-matching are visible, but are not large enough to explain the aperture restriction. 


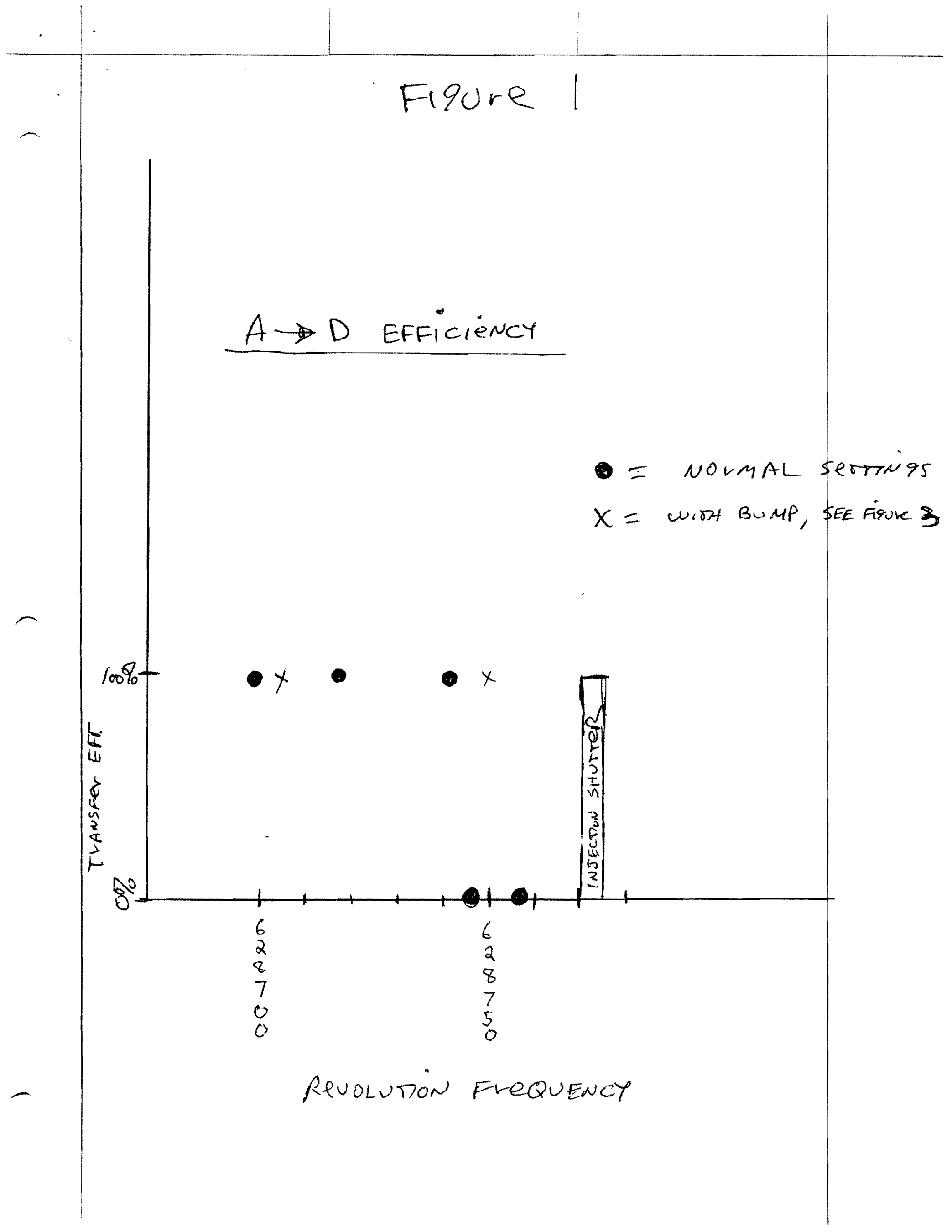


BEAM OH EXTRACTION ORBIT - SHOWS DUTLINE DF SHUTTER

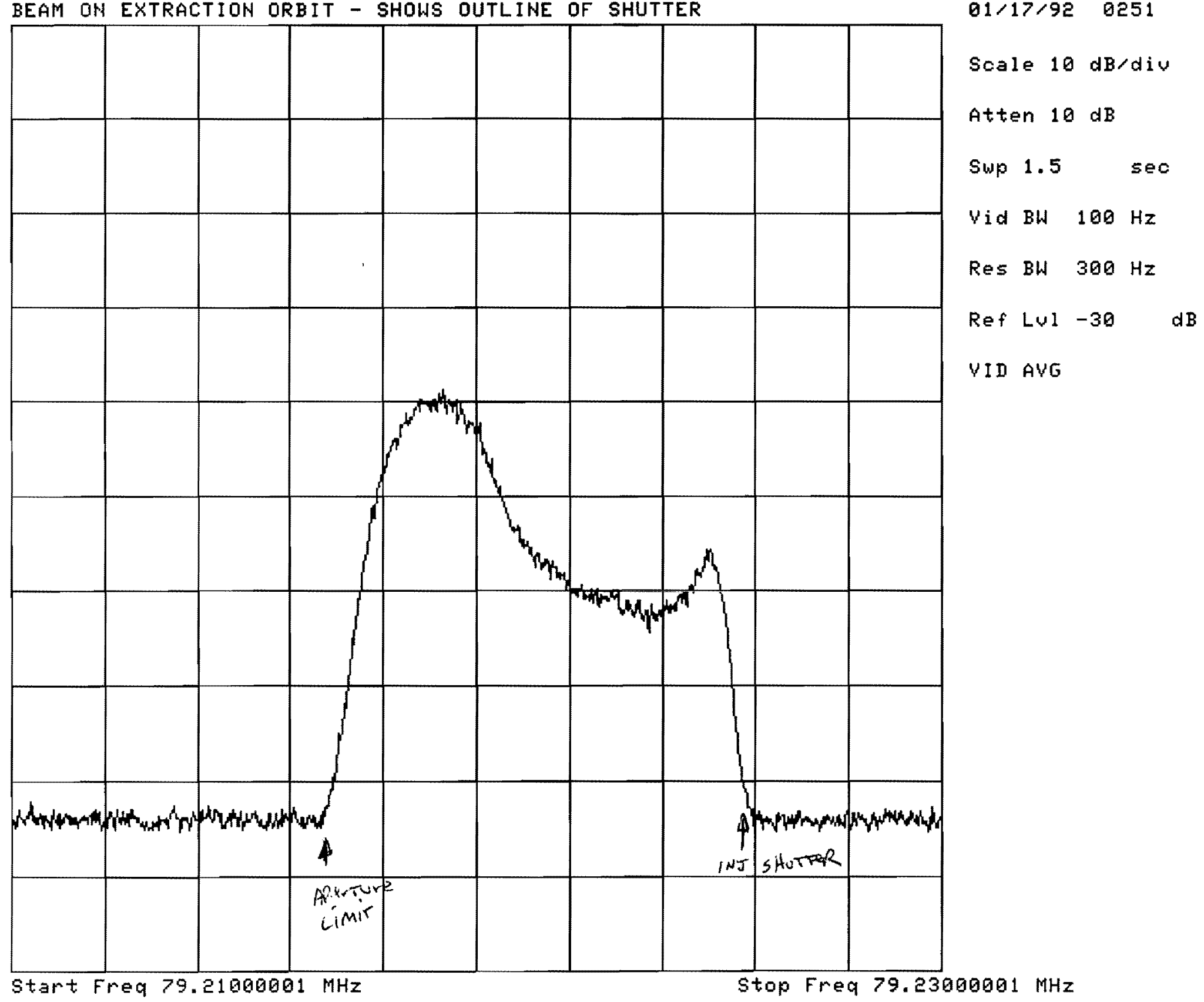





\section{BUMlP (w) $\pi \cdot d$ dx If}

)

\section{ACEUNULATOR CLOSED ORBIT}

\section{〈HORIZOHTAL )}

\section{A: R3HLFB}

$X:$ POFTT

6.963655

5947.142

CO Date/Time: 10/19/91 0041:55

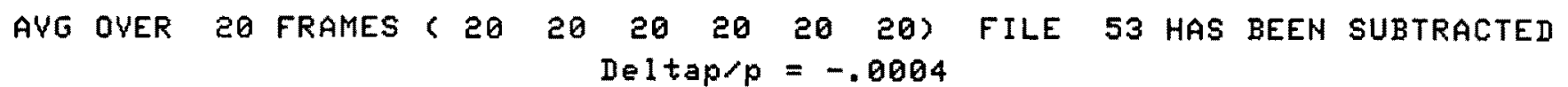

BEAM POSITIONS (mm)

\begin{tabular}{|c|c|c|c|c|c|c|c|c|c|c|c|}
\hline $\begin{array}{l}A 1 Q 1 \\
A 1 Q 3 \\
A 1 Q 4 \\
A 1 Q 6 \\
A 1 Q 8 \\
A 1 Q 10 \\
A 1 Q 11 \\
A 1 Q 14\end{array}$ & $\begin{array}{l}1.11 \\
.73 \\
.51 \\
-2.58 \\
-.98 \\
9.23 \\
11.1 \\
10.69\end{array}$ & $\begin{array}{l}\text { A2Q14 } \\
A 2 Q 11 \\
A 2 Q 10 \\
A 2 Q 8 \\
\text { A2Q6 } \\
\text { A2Q4 } \\
\text { A2Q3 } \\
\text { A2Q } 1\end{array}$ & $\begin{array}{c}6.09 \\
3.99 \\
4.28 \\
-.99 \\
-1.79 \\
.99 \\
.35 \\
.39\end{array}$ & $\begin{array}{l}\text { A3Q1 } \\
A 3 Q 3 \\
\text { A3Q4 } \\
A 3 Q 6 \\
\text { A3Q8 } \\
A 3 Q 10 \\
\text { A3Q11 } \\
\text { A3Q14 }\end{array}$ & $\begin{array}{l}.41 \\
-1.13 \\
-2.15 \\
\text { NO BEAM } \\
-.37 \\
-4.3 \\
-2.9 \\
\text { NO BEAM }\end{array}$ & $\begin{array}{l}A 4 Q 14 \\
A 4 Q 11 \\
A 4 Q 10 \\
A 4 Q 8 \\
A 4 Q 6 \\
A 4 Q 4 \\
A 4 Q 3 \\
A 4 Q 1\end{array}$ & $\begin{array}{l}-13.44 \\
-9.45 \\
-17.46 \\
0 \\
-1.89 \\
-1.12 \\
-.35 \\
-.43\end{array}$ & $\begin{array}{l}\text { A5Q1 } \\
A 5 Q 3 \\
A 5 Q 4 \\
A 5 Q 6 \\
A 5 Q 8 \\
A 5 Q 10 \\
A 5 Q 11 \\
\text { A5Q14 }\end{array}$ & $\begin{array}{l}-.38 \\
.33 \\
-1.49 \\
-2 \\
-.7 \\
-6.4 \\
-7.87 \\
-15.27\end{array}$ & $\begin{array}{l}A 6 Q 14 \\
A 6 Q 11 \\
A G Q 10 \\
A 6 Q 8 \\
A 6 Q 6 \\
A G Q 4 \\
A 6 Q 3 \\
A 6 Q 1\end{array}$ & $\begin{array}{l}-11.09 \\
-7.15 \\
-7.45 \\
.37 \\
-2.44 \\
-1.13 \\
-.39 \\
-.44\end{array}$ \\
\hline
\end{tabular}

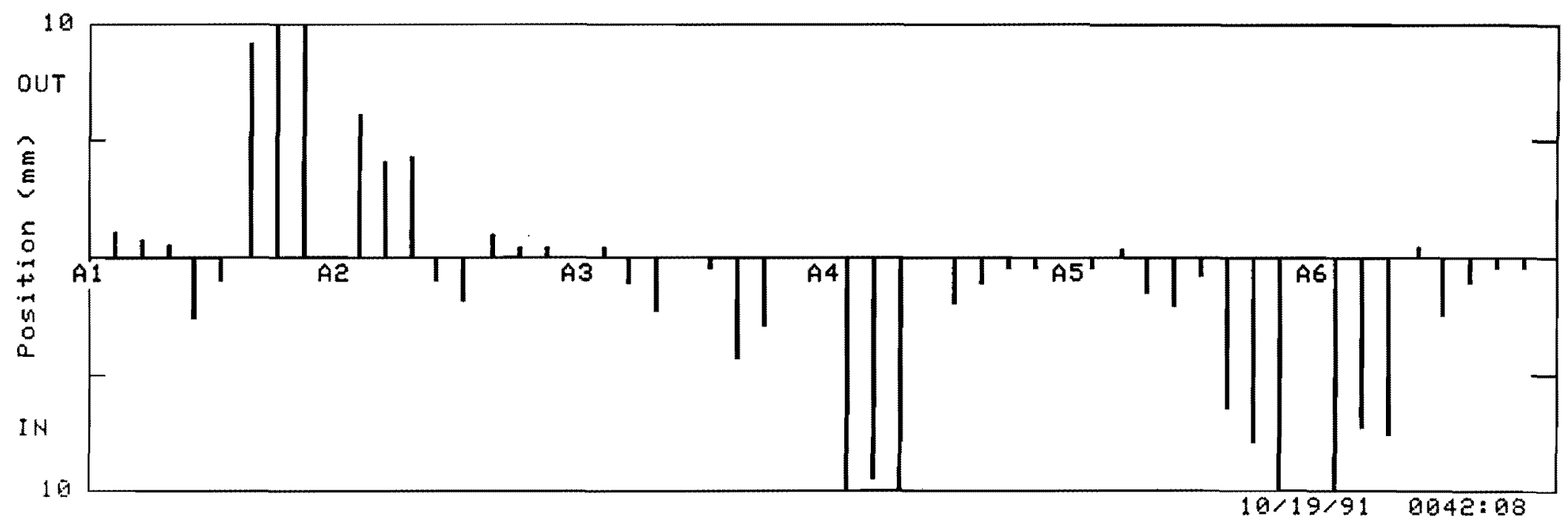


MULTIPLE TURH DISPLAY, SECTOR $1 \mathrm{D}$

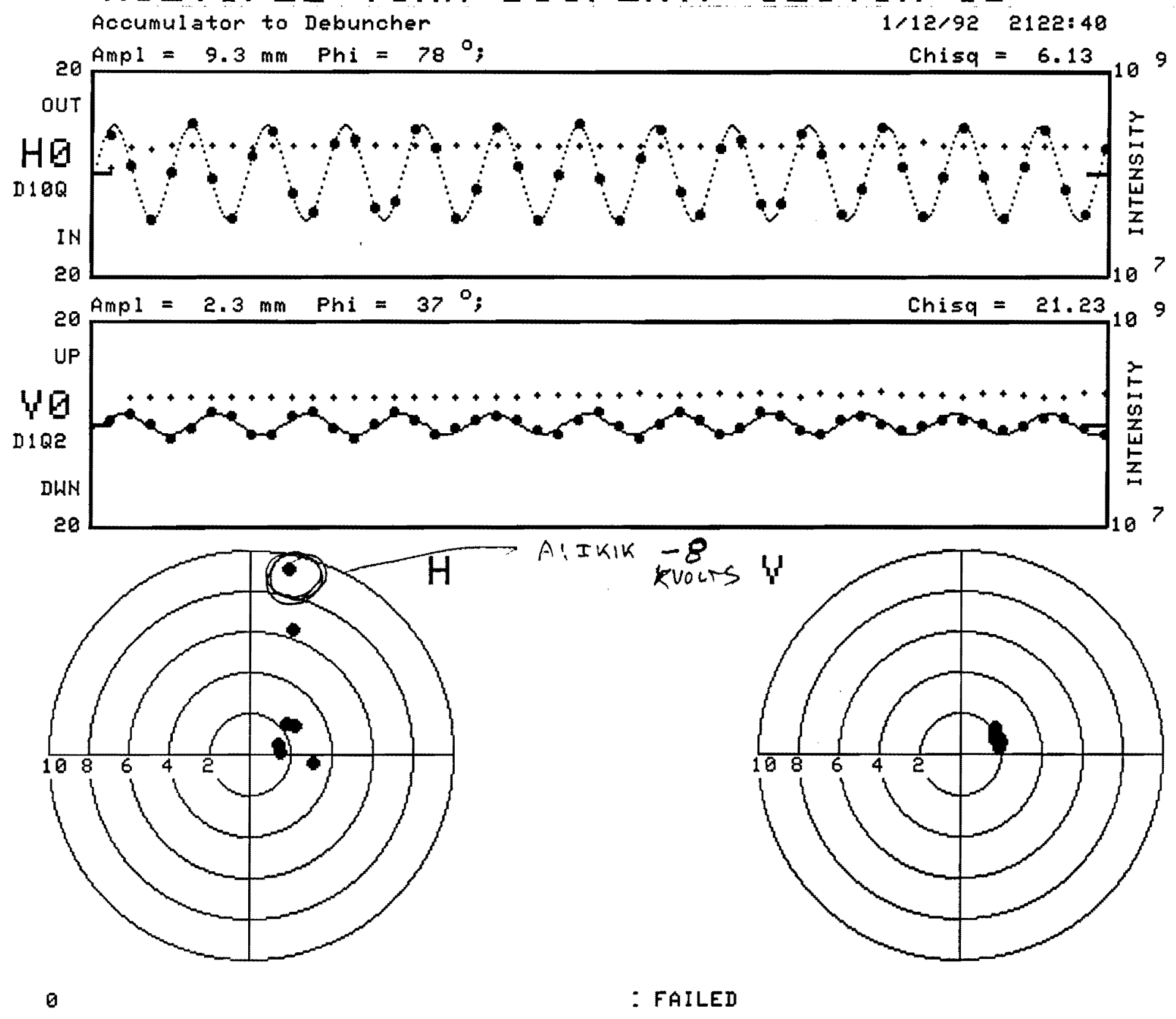


MULTIPLE TURN DISPLAY, SECTOR 10 Accumulator to Debuncher 1/12/92 2129:09

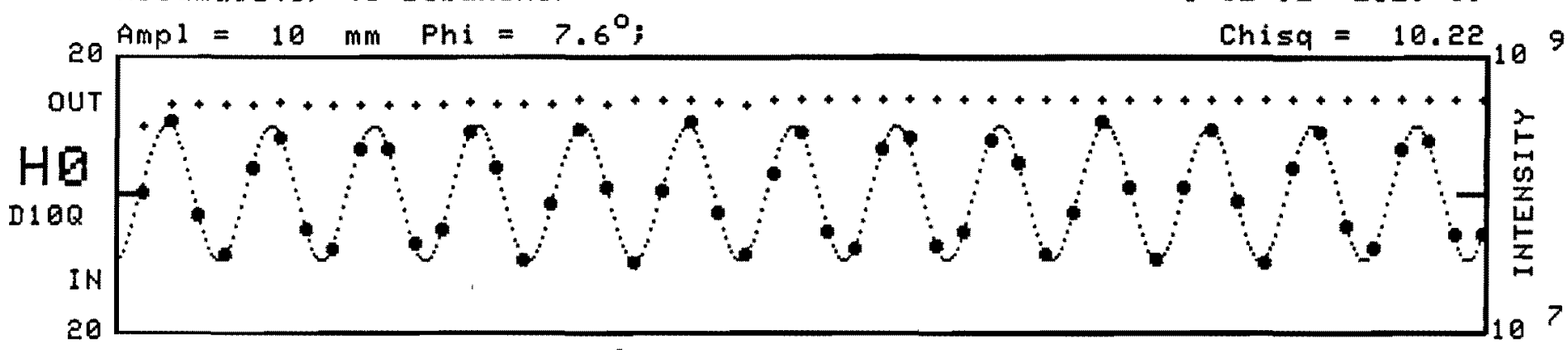

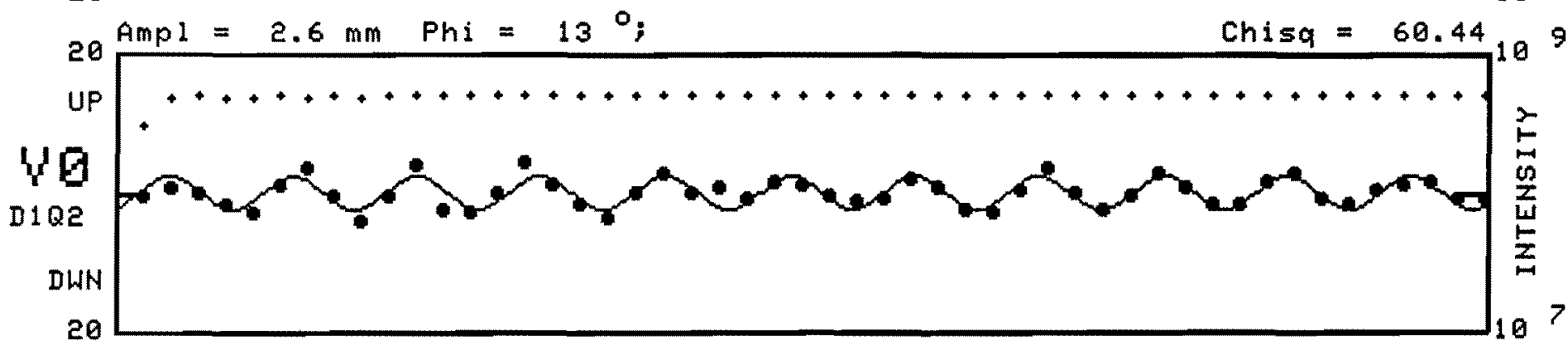

D:FKiK
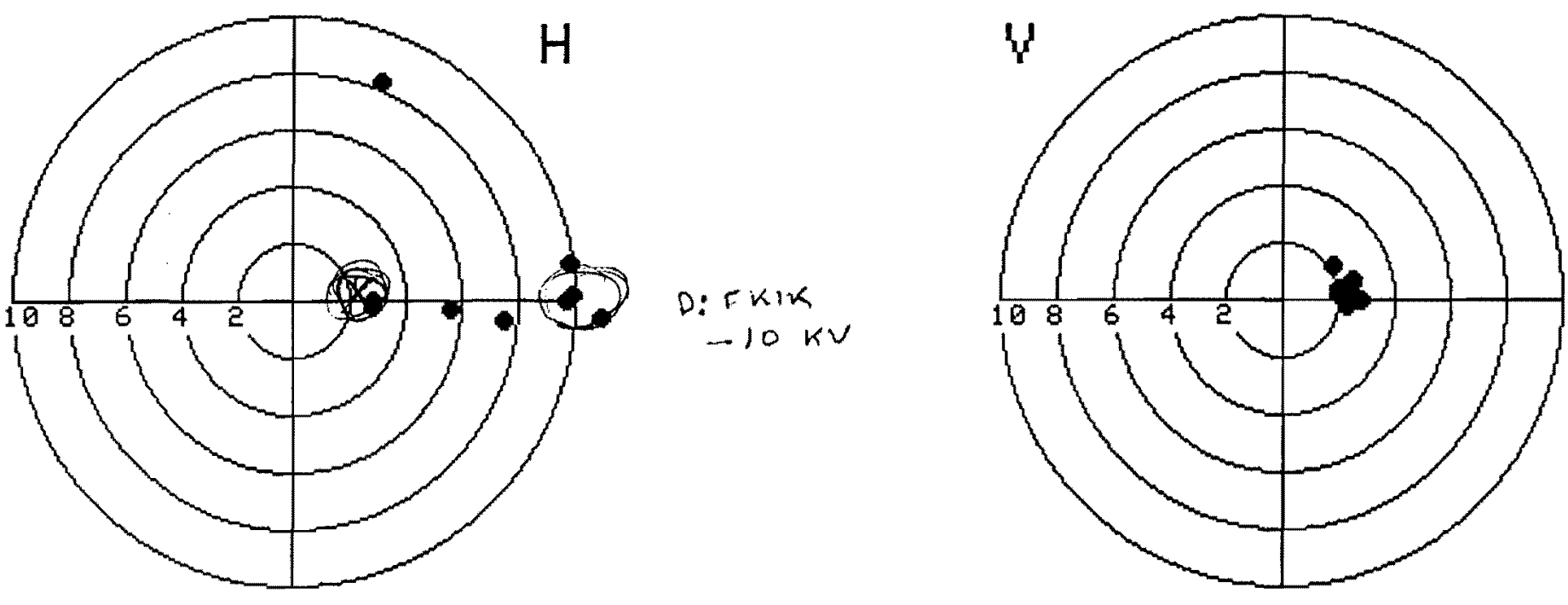
MULTIPLE TURN DISPLAY: SECTDR 1 D

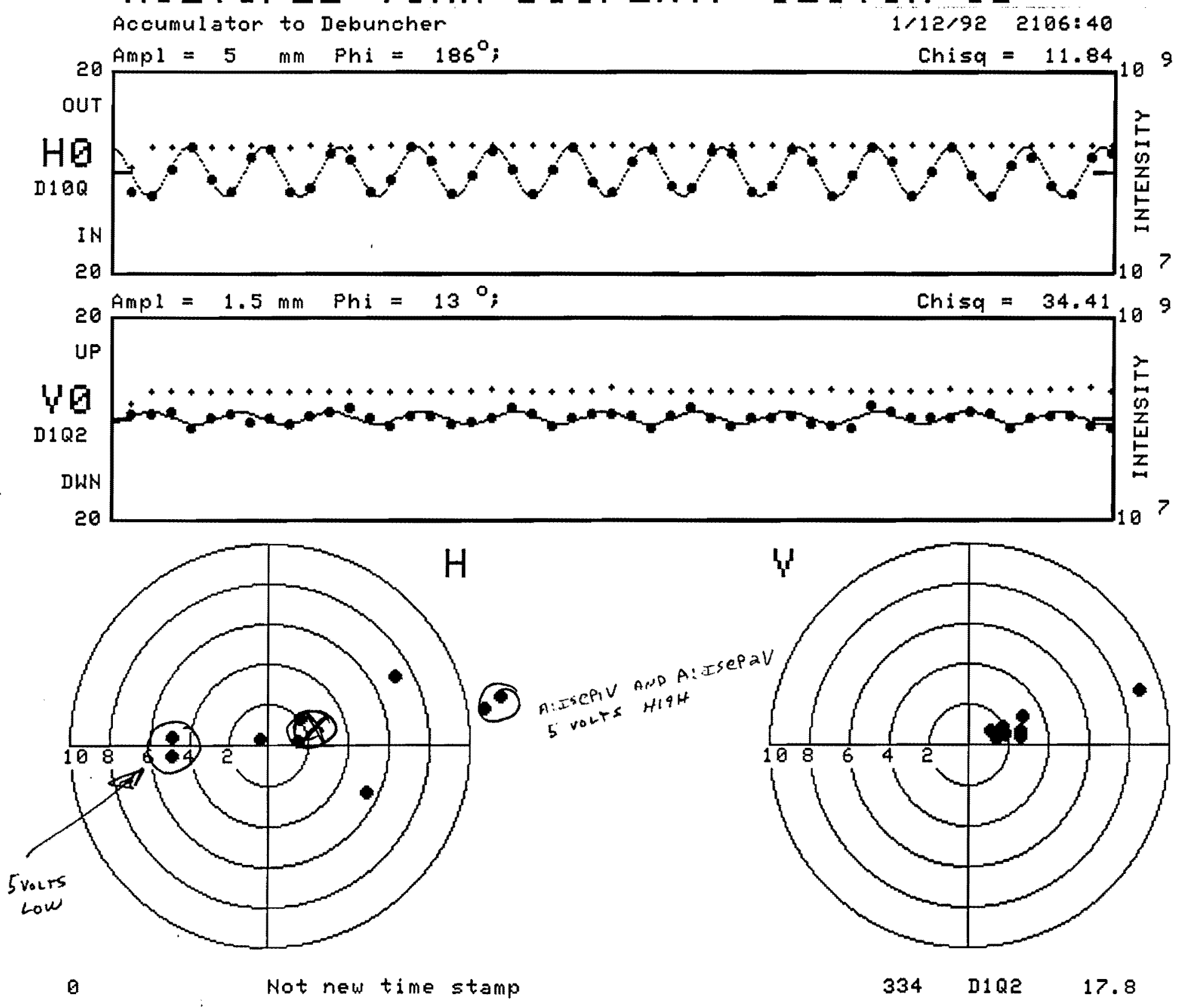


MULTIPLE TURH DISPLAY, SECTOR $1 \mathrm{D}$

Accumulator to Debuncher
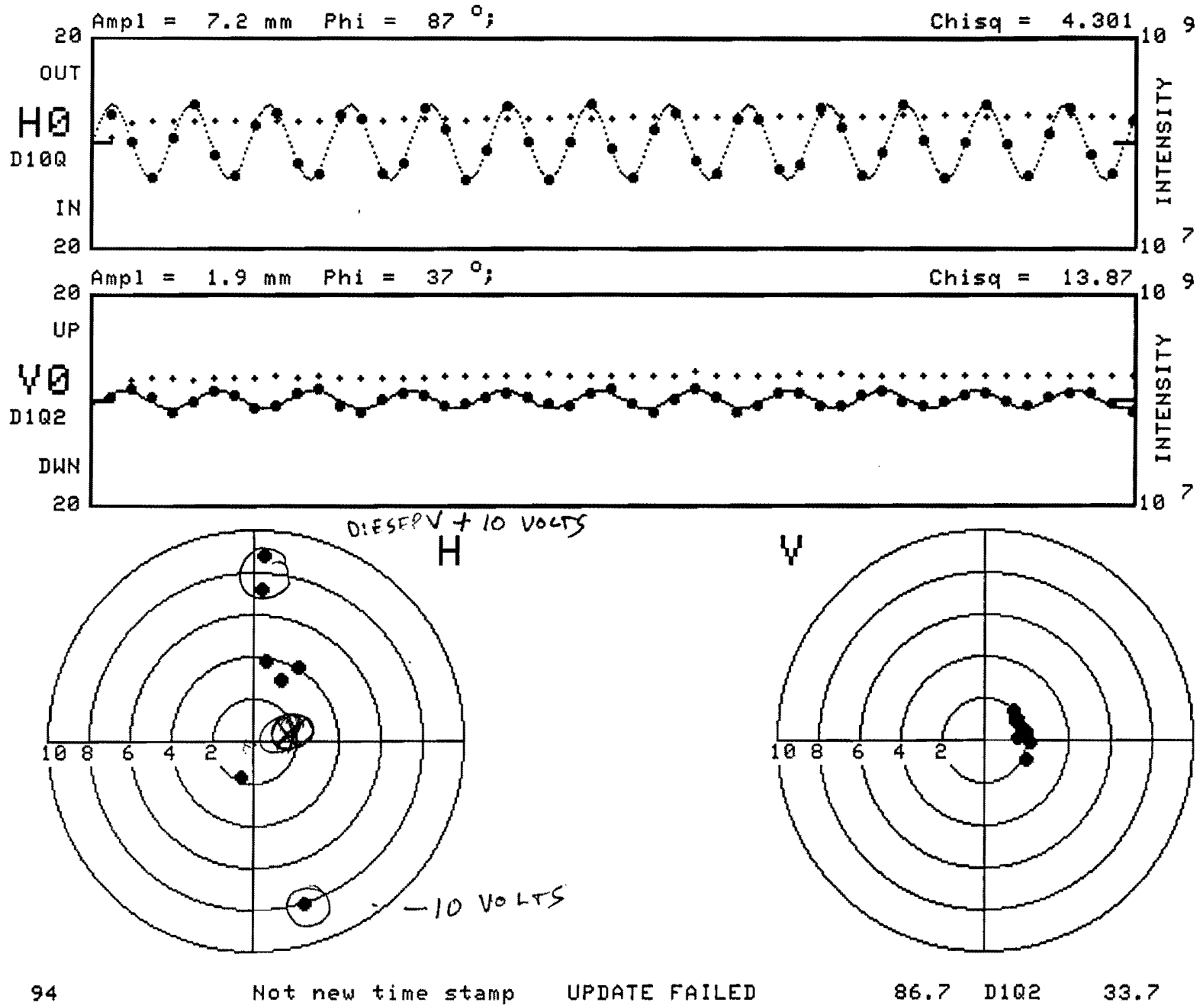
MULTIPLE TURH DISPLAY SECTOR 1 D Accumulator to Debuncher
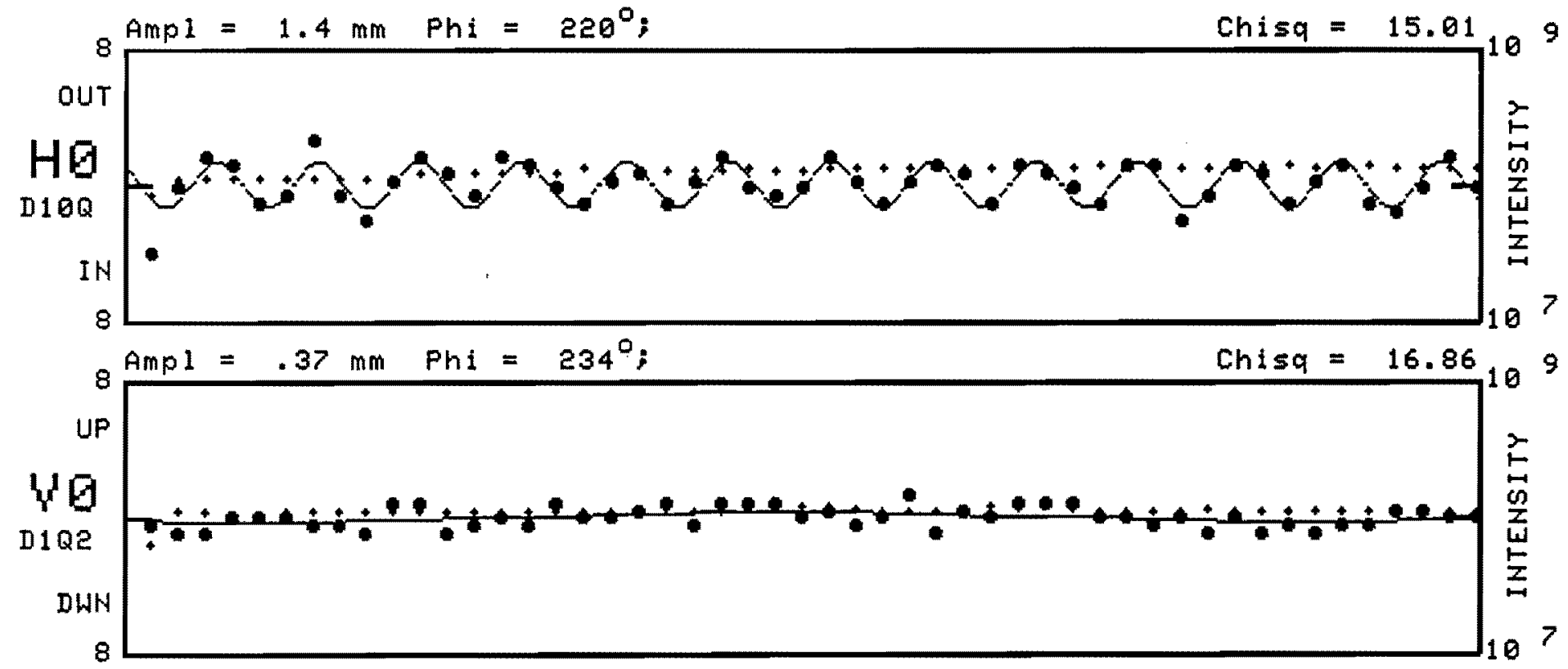

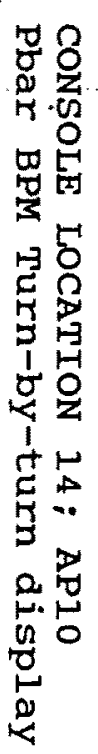

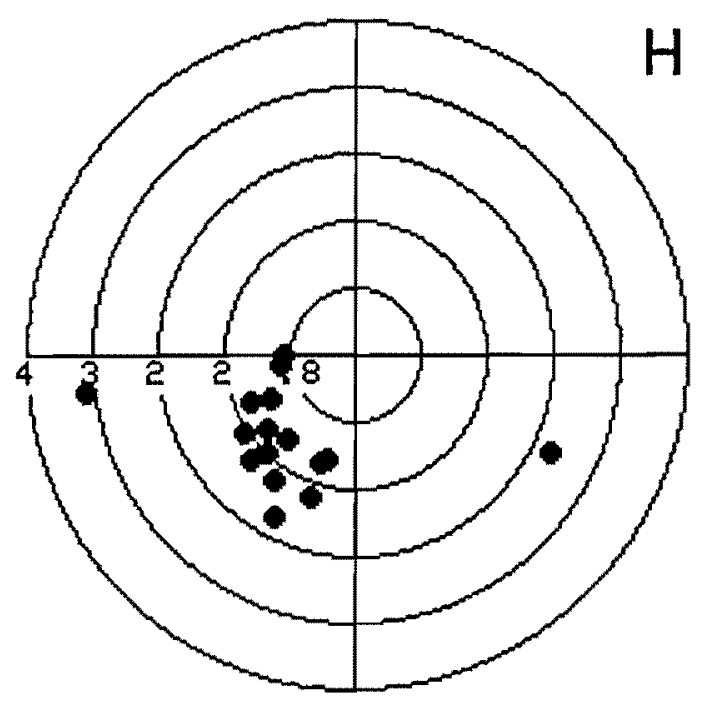

H

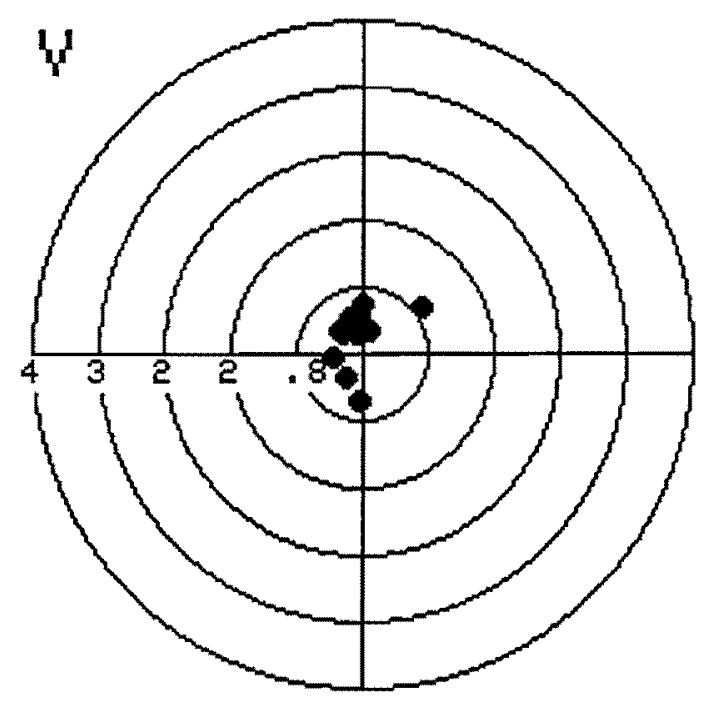


MULTIPLE TURH DISPLAY, SECTOR 1 I Acoumulator to Debuncher

1/12/92 2208:42
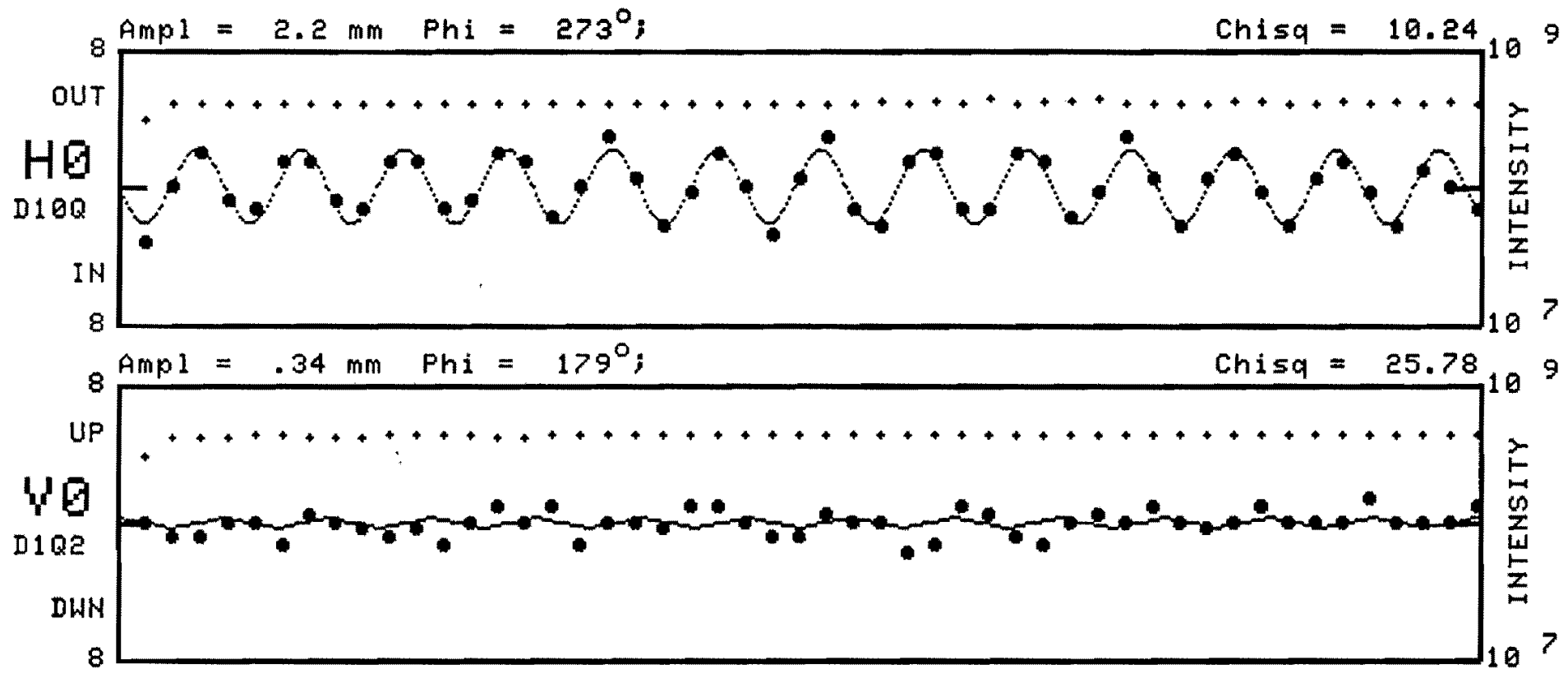

9
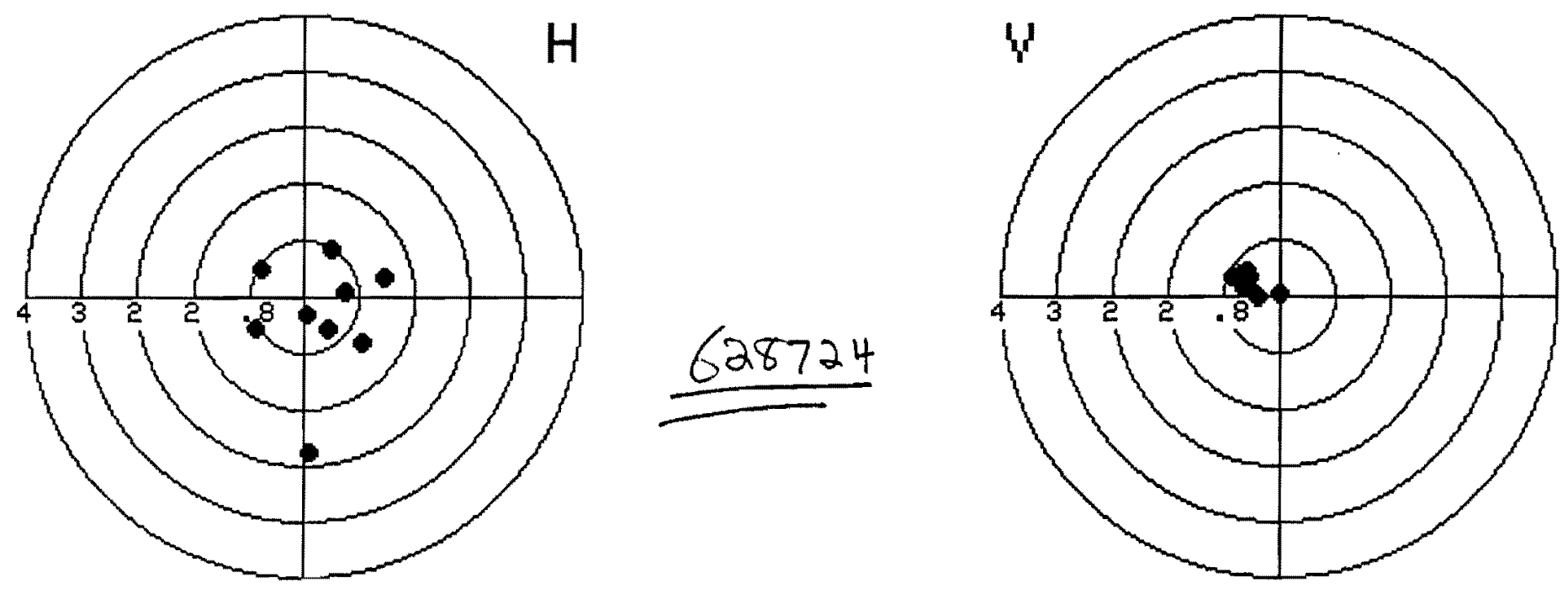

a

Not new time stamp 
MULTIPLE TURH DISPLAY, SECTOR 10 Accumulator to Debuncher
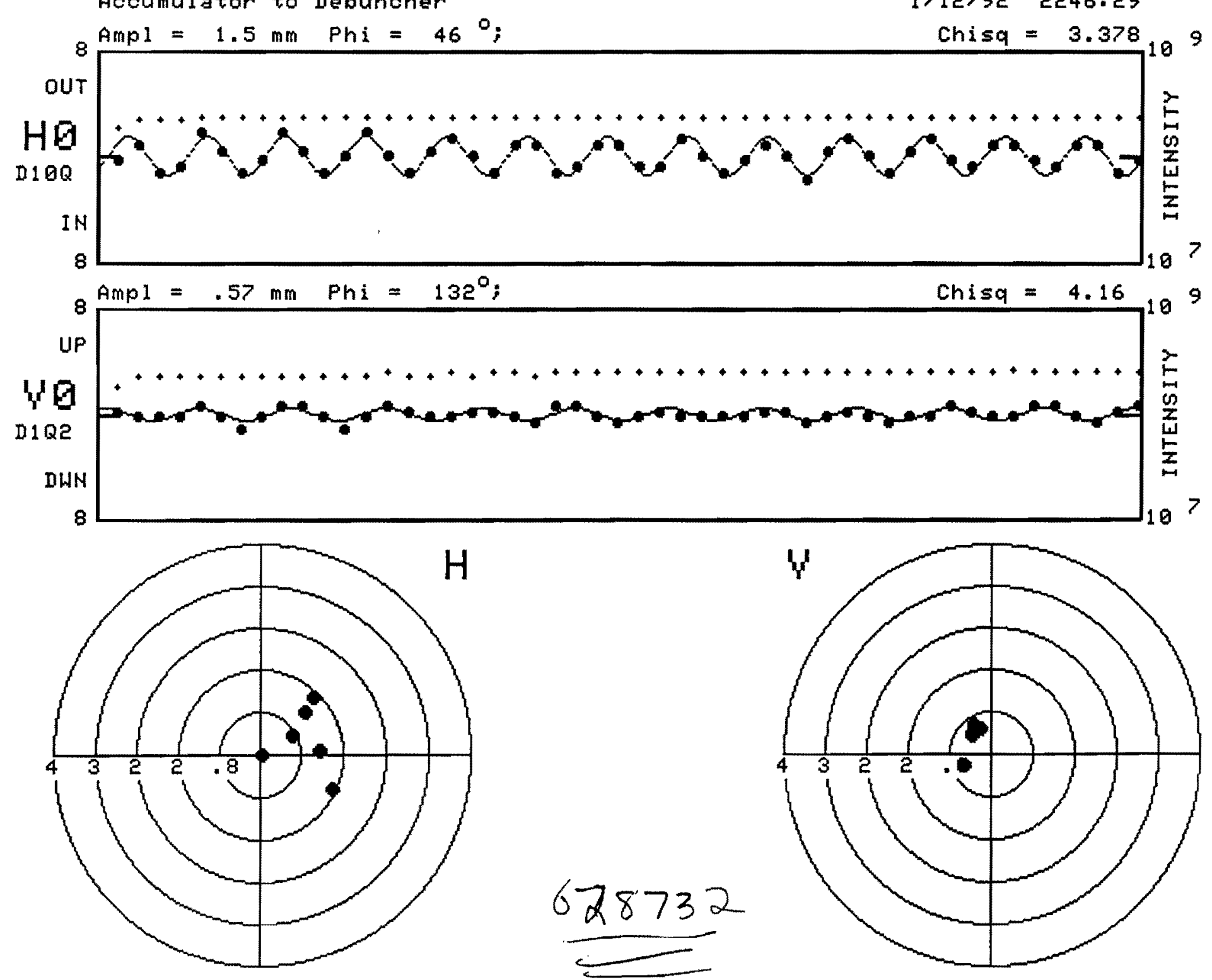

0

Not new time stamp 
MULTIPLE TURH DISPLAY, SECTOR $1 \mathrm{D}$ Acoumulator to Debunoher $1 / 12 / 92$ 2345:59
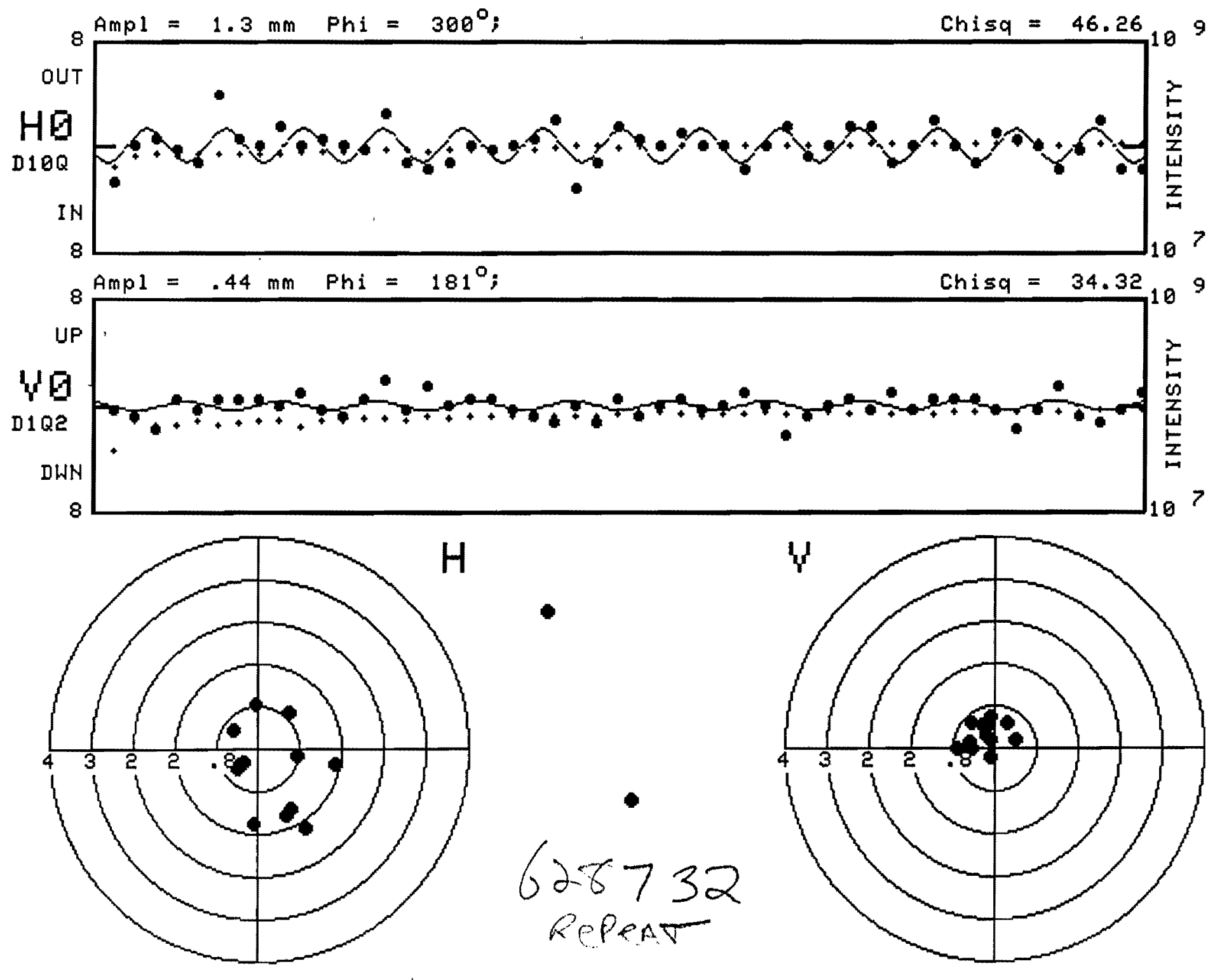
MULTIPLE TURH DISPLAY, SECTOR 1 D
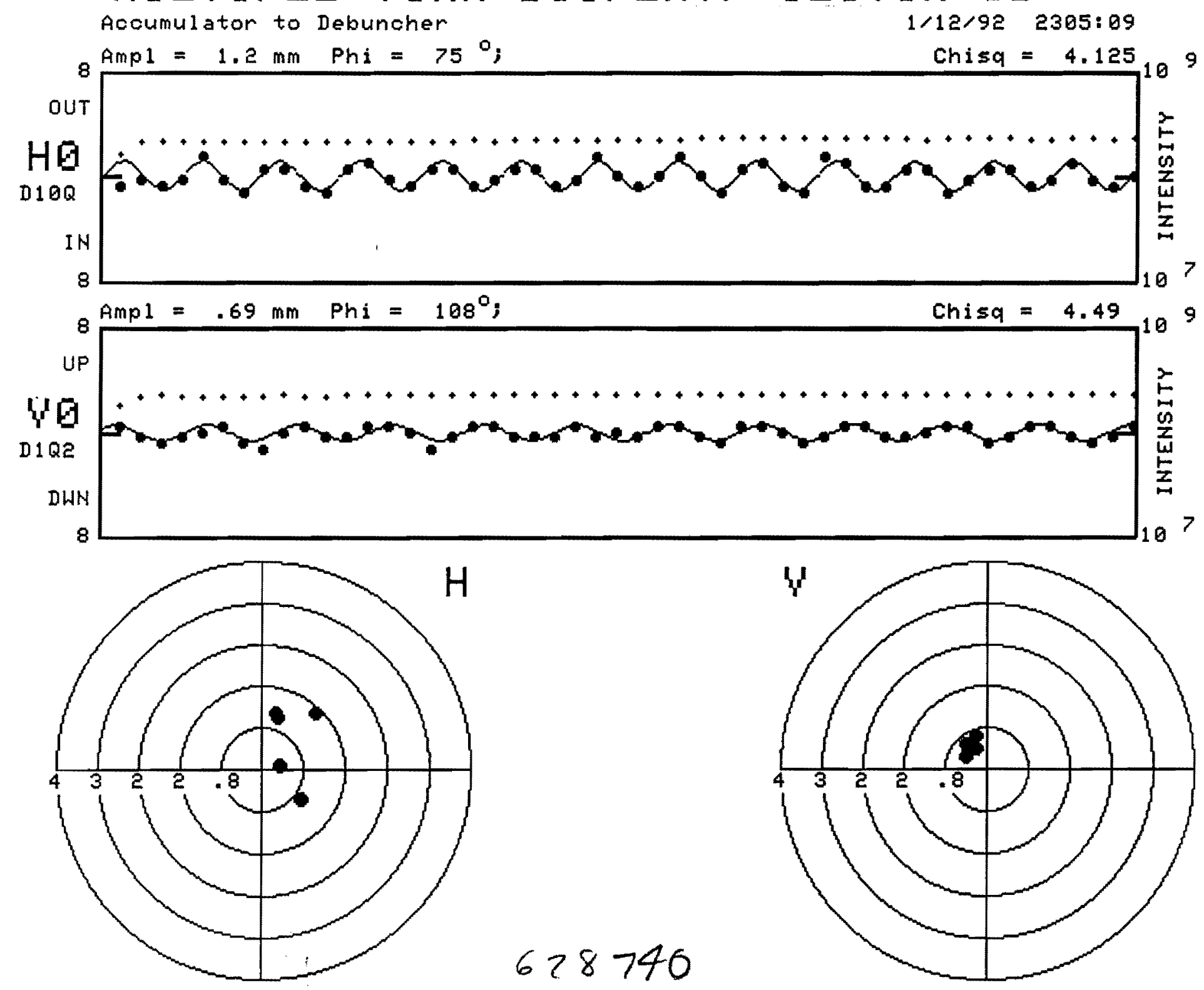

628740

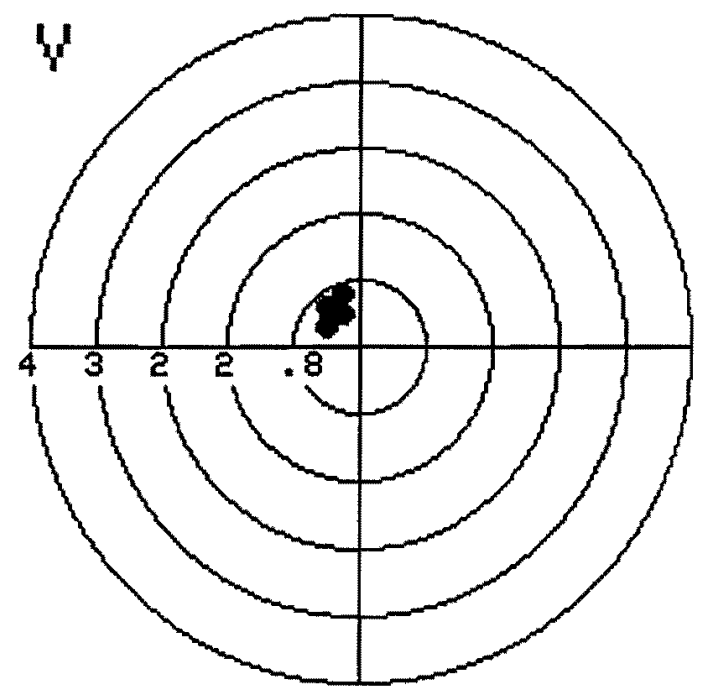


MULTIPLE TURH DISPLAY, SECTOR 1 D Accumulator to Debuncher $1 / 12 / 92 \quad 2313: 59$
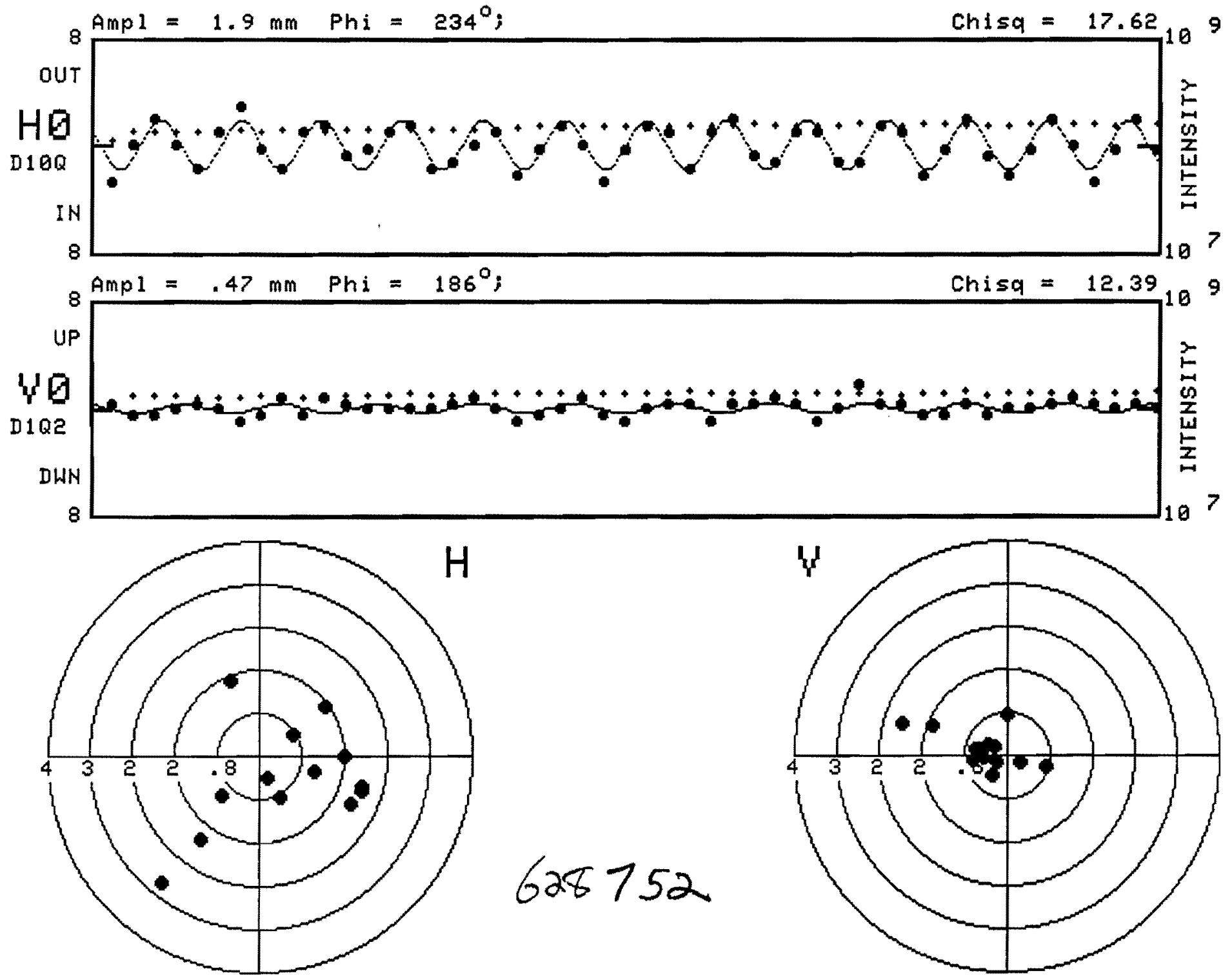

628752

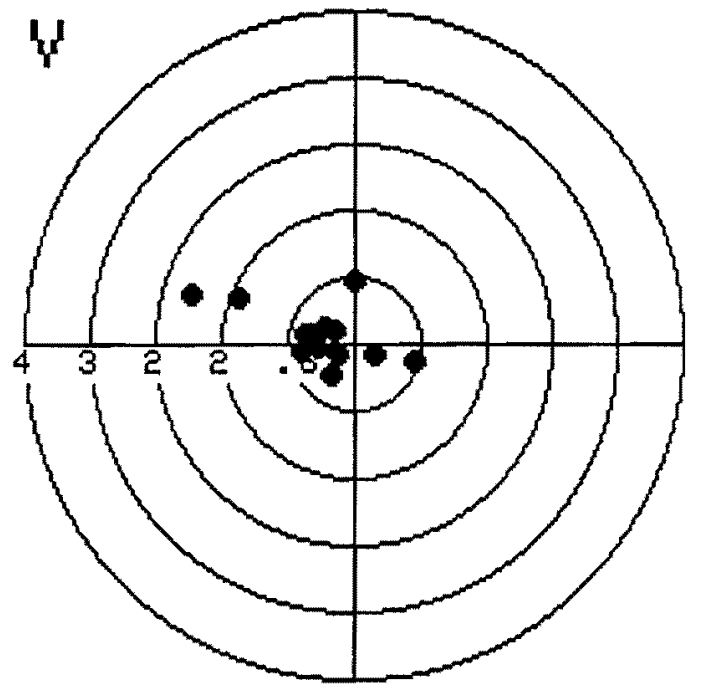

6

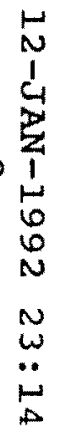

